
\title{
25 Research Soure \\ Fatigue Design Curves for Laser-Metal-Deposited Type 420 Stainless Steel and Effect of an Interval during Deposition Process
}

Yoshihiko Uematsu ( $\nabla$ yuematsu@gifu-u.ac.jp )

Gifu University https://orcid.org/0000-0003-4161-3738

Ryosuke Sasaki

OKUMA Corporation, Oguchi-cho, Niwa-gun

Toshifumi Kakiuchi

Gifu University

Seiei Yamamoto

OKUMA Corporation, Oguchi-cho

Akihiro Zensho

OKUMA Corporation, Oguchi-cho

Ri-ichiro Sano

Graduate School of Engineering, Gifu University

\section{Research Article}

Keywords: Additive manufacturing, Laser metal deposition, Fatigue, Design fatigue curve, Type 420 stainless steel.

Posted Date: May 28th, 2021

DOl: https://doi.org/10.21203/rs.3.rs-386020/v1

License: (9) This work is licensed under a Creative Commons Attribution 4.0 International License. Read Full License

Version of Record: A version of this preprint was published at The International Journal of Advanced Manufacturing Technology on July 14th, 2021. See the published version at https://doi.org/10.1007/s00170-021-07605-2. 


\section{Abstract}

Fully-reversed axial loading fatigue tests were conducted using type 420J1 martensitic stainless steel. The specimens were additively manufactured by a laser metal deposition (LMD) process. The results were compared with conventionally-manufactured (CMed) type 420J2 stainless steel. According to the axial loading fatigue test results, the fatigue strengths of the laser-metal-deposited (LMDed) specimens were nearly comparable to those of the CMed specimens. Fractographic analyses revealed that processinduced defects were hardly seen at the fatigue crack initiation sites of the LMDed specimens. It indicates that defect-free deposition was possible by the LMD process. On the other hand, when the LMD specimens experienced intervals during deposition processes, local softening occurred due to the tempering of the building plate. Fatigue tests revealed that the interval during LMD process had detrimental effect on the fatigue strengths due to the local softening. The upper and lower bounds of $S-N$ curves were proposed as fatigue design curves for the samples with and without the interval during LMD process.

\section{Introduction}

Additive manufacturing (AM) is an attractive method to fabricate near-net-shape components with complex shapes [1],[2]. Powder bed fusion (PBF) and directed energy deposition (DED) are two major methods in the several AM procedures, which are used for the fabrication of load-bearing mechanical components [3]. Laser metal deposition (LMD) is one of the DED processes, in which high power laser is used to melt metal powder [4] [6]. LMD has some merits, for example, large components can be fabricated because inert gas chamber is not necessary like PBF. Furthermore, since powder supplying route can be changed easily, multi-layered components can be made [7],[8]. LMD is sometimes used for the repairmen of dies and turbine blades [9],[10], because it is easy to mold powder on the bulk components. Recently, multitasking LMD machines are developed [11], in which a 5-axis machining center is integrated into an LMD processing area. Multitasking LMD machine can fabricate final products by alternating procedures of $A M$ and machining in the same processing area. It is expected that multitasking machines will be widely used for the fabrication of mechanical components. Therefore, it is important to understand the fatigue properties of additively-manufactured (AMed) components. There are several works about fatigue properties of AMed materials of high strength stainless steels [12] [17]. For example, Yadollahi et al. conducted axial loading fatigue tests and fatigue crack propagation tests using AMed 17 - 4 precipitation hardening stainless steel. They revealed that fatigue cracks predominantly initiated at process-induced defects, such as lack-of-fusion defects, and consequently, fatigue lives were successfully predicted using linear elastic facture mechanics assuming crack growth from initial defects. However, all samples were fabricated by PBF type selective laser melting (SLM) in the above references [12] [17]. Bandyopadhyay et al. investigated fatigue properties and effect of building conditions in Ti6Al-4V fabricated by laser engineered net shaping $\left(\right.$ LENS $\left.^{T M}\right)$ [18], one of DED processes, but researches about fatigue of the laser-metal-deposited (LMDed) high strengths stainless steels are missing. 
It is known that several building conditions, such as laser hatching [19], building direction [20] [22], strut orientation [23], scanning velocity [24], laser power [25], etc., can affect mechanical properties of built samples. The process interval during deposition could be also the influencing factor on the mechanical properties [26]. Stoll et al. revealed that the tensile properties decreased $13 \sim 18 \%$ by the interruption during building in selective-laser-melted (SLMed) type 316 austenitic stainless steel [26]. They also reported that the amount of degradation in tensile properties was dependent on the building direction. Consequently, it can be said that the interval during deposition process could be one of the influencing factors on the mechanical properties of AMed materials. However, the effect of building interval on the fatigue properties of LMDed high strength stainless steels is not investigated yet.

In the present study, a multitasking LMD machine, MU-6300V LASER EX (OKUMA Corporation), was used for the fabrication of the samples using powder of Type 420 martensitic stainless steel as shown in Fig. 1. Axial loading tensile fatigue tests were conducted to evaluate fatigue properties of the LMDed high strength stainless steel. In addition, deposition process was once interrupted to cool the building plate down to the room temperature, and then the deposition was resumed to evaluate the effect of the intervals during deposition process on the fatigue properties.

\section{Experimental Details}

\subsection{Materials and specimens}

The powder material is Type 420 11 martensitic stainless steel. The reference material is conventionallymanufactured (CMed), namely vacuum melted Type 420J2. Type 420J2 was received in the annealed condition. Therefore, some samples were annealed at $1040^{\circ} \mathrm{C}$ for $15 \mathrm{~min}$ followed by oil quenching, and subsequently, tempered at $150^{\circ} \mathrm{C}$ for 2 hours followed by air cooling. The chemical compositions of the materials are summarized in Table 1.

Table 1

Chemical compositions of materials.

\begin{tabular}{|lllllllll|}
\hline & C & Si & Mn & P & S & Cr & Ni & Fe \\
\hline 420J1 LMD & 0.23 & 0.59 & 0.31 & 0.017 & 0.008 & 13.5 & - & Bal. \\
\hline 420J2 & 0.31 & 0.44 & 0.43 & 0.018 & 0.005 & 13.16 & 0.25 & Bal. \\
Reference & & & & & & & & \\
\hline
\end{tabular}

Figure 2 shows the LMD process. Firstly, Type 420J1 powder was deposited on the carbon steel base plate to form the plate with the length of 130, height of 30 and thickness of $4 \mathrm{~mm}$ as shown in Fig. 2(a). Subsequently, the LMDed plate was machined into the plate with the length of 130, height of 26 and thickness of $2.5 \mathrm{~mm}$ (Fig. 2(b)) in the same processing area of a multitasking LMD machine. Finally, the 
plate was cut from the base plate as shown in Fig. 2(c). The fatigue specimen, whose configuration is shown in Fig. 3, was cut from the plate of Fig. 2(c) by wire cut discharge machining. The building direction was perpendicular to the longitudinal direction of a fatigue specimen. The LMD conditions are summarized in Table 2. In some samples, the LMD process was interrupted at the dotted line in Fig. 3 , namely at the center of the specimen, to investigate the effect of the interval during deposition process. When the temperature of the building plate became the same with the room temperature, the deposition was resumed.

Table 2

LMD conditions.

\begin{tabular}{|lllllll|}
\hline $\begin{array}{l}\text { Laser } \\
\text { oscillator }\end{array}$ & $\begin{array}{l}\text { Laser } \\
\text { power }\end{array}$ & $\begin{array}{l}\text { Laser spot } \\
\text { size }\end{array}$ & $\begin{array}{l}\text { Feed } \\
\text { speed }\end{array}$ & $\begin{array}{l}\text { Vertical } \\
\text { pitch }\end{array}$ & $\begin{array}{l}\text { Horizontal } \\
\text { pitch }\end{array}$ & $\begin{array}{l}\text { Number of } \\
\text { layer }\end{array}$ \\
\hline disk laser & 1500 & $\varphi 3.5$ & 800 & 0.35 & 1.7 & 84 \\
$($ Yb: YAG) & W & $\mathrm{mm}$ & $\mathrm{mm} / \mathrm{min}$ & $\mathrm{mm}$ & $\mathrm{mm}$ & \\
\hline
\end{tabular}

\subsection{Experimental procedures}

The microstructures were etched by Picric acid-ethanol solution and observed by optical and scanning electron microscopes. Hardness distribution was measured by a micro Vickers hardness tester at the load of $4.9 \mathrm{~N}$ and dwell time of 15 seconds with the adjacent spacing of $1 \mathrm{~mm}$. Axial loading fatigue tests were conducted using an electro-hydraulic fatigue testing machine with the capacity of $50 \mathrm{kN}$. The fatigue load waveform was sinusoidal with the frequency of $20 \mathrm{~Hz}$ and stress ratio $R=\sigma_{\min } / \sigma_{\max }=-1$ (fully reversed loading). All fatigue specimens were polished before the fatigue tests by the emery paper from the grade of \#80 to \#2000, and buff finished to obtain mirror surface. Residual stress was measured by an X-ray diffraction method using Bulker M03XHF22. The conditions of X-ray diffraction are summarized in Table 3.

Table 3

XRD conditions.

\begin{tabular}{|lllllll|}
\hline Plane & Angle 20 & Radiation & $\begin{array}{l}\text { Tube } \\
\text { voltage }\end{array}$ & $\begin{array}{l}\text { Tube } \\
\text { current }\end{array}$ & $\begin{array}{l}\text { Sampling } \\
\text { interval }\end{array}$ & $\begin{array}{l}\text { Scanning } \\
\text { speed }\end{array}$ \\
\hline $\mathrm{a} 221$ & $\begin{array}{l}156.0 \\
\text { deg. }\end{array}$ & $\mathrm{Cr}-\mathrm{Ka}$ & $50 \mathrm{kV}$ & $40 \mathrm{~mA}$ & $0.050 \mathrm{deg}$. & $4.0 \mathrm{deg} . / \mathrm{min}$ \\
\hline
\end{tabular}

\section{Results}

\subsection{Microstructures}

The microstructures of the reference material, CMed Type 420J2, are shown in Fig. 4, where Figs. 4(a) and 4 (b) are annealed and quenched conditions, respectively. Ferritic microstructure is dominant in the 
annealed condition (Fig. 4(a)). On the other hand, martensitic microstructure appeared in Fig. 4(b) due to the quenching and tempering. Carbides are dispersed in both microstructures, while the number of carbides is smaller in Fig. 4(b), because carbon is under supersaturated solid solution in martensite microstructure. Figure 5 indicates the microstructures of the LMDed Type 420 J1 observed on the cross section as schematically shown in the upper figure. The interval during deposition procedure was given near the center of the cross section (at the arrow in Fig. 5(a)) to lower the temperature of the building plate to the room temperature. The magnified views of the microstructures at the locations " $A$ " and " $B$ " in Fig. 5(a) are shown in Figs. 5(b) and 5(c), respectively, which are far away from the interval where the effect interval on the microstructure is negligible. They reveal that martensitic microstructures developed at both locations due to re-solidification of melted powder. Figure 6(a) shows the microstructure in the rectangular area of Fig. 5(a) including the location of interval. It should be noted that the shade of the gray color changed slightly across the interval. The magnified views at the areas " $A$ ", " $B$ " and " $C$ " in Fig. 6(a) are shown in Figs. 6(b), 6(c) and 6(d), respectively. The martensitic microstructures are dominant at all locations, and the microscopic appearances of martensitic microstructures are nearly the same in Figs. 5(b) and 5(d), and Figs. 6(b) 6(d). As will be mentioned in the next section, local softening occurred by the interval in spite of the similar martensitic microstructures with and without interval. It means that cementite distribution in martensite might have changed, and weather building interval have existed of not cannot be distinguished by the microstructural observation using an SEM.

\subsection{Static mechanical properties}

The average Vickers hardness of the reference material, CMed Type 420J2, was 171 HV and 532 HVfor the annealed and quenched samples, respectively, and the average hardness of the LMDed Type 420J1 was $573 H V$. Subsequently, Vickers hardness profiles were measured on the cross section of the LMDed samples with and without the interval as shown in Fig. 7. It should be noted that local softening occurred due to the interval, and the softened area was wider in the area before the interval (left side of the interval). Typical stress-strain curves of the CMed and LMDed specimens are shown in Fig. 8, and the properties are summarized in Table 4. The mechanical properties of the CMed specimen increased by the quenching, and those of the LMDed specimen are similar to the quenched reference material, while the elongation and reduction of area, namely ductility, were lower (Table 4). The residual stresses parallel to the longitudinal direction were measured using the plate shown in Fig. 2(c) before the wire cutting of a fatigue specimen. The results are shown in Fig. 9 as a function of the distance from the center of the plate. Residual stress distributions are different depending on the building conditions, where the compressive residual stress is dominant without building interval, and tensile residual stress appears by the interval. The residual stress is strongly affected by the heat history, while the precise mechanism in the change of residual stress by the interval is not clear in the present case. However, it should be noted that similar compressive residual stresses appear at the center of the plates, namely the center of the gauge section of fatigue specimens, in both specimens with and without building interval, which would be the controlling factor of the fatigue strength shown in the next section. 
Table 4 Mechanical properties

\begin{tabular}{ccccccc}
\hline \multirow{2}{*}{ Material } & $\begin{array}{c}0.2 \% \text { proof } \\
\text { stress } \\
\sigma 0.2(\mathrm{MPa})\end{array}$ & $\begin{array}{c}\text { Tensile } \\
\text { strength }\end{array}$ & $\begin{array}{c}\text { Elongation } \\
\delta(\%)\end{array}$ & $\begin{array}{c}\text { Reduction } \\
\text { of area } \\
\varphi(\%)\end{array}$ & $\begin{array}{c}\text { Vickers } \\
\text { hardness }\end{array}$ \\
\hline \multicolumn{2}{c}{ LMD } & 1152 & 1737 & 5.9 & 6.6 & 573 \\
\hline \multirow{2}{*}{$\begin{array}{c}420 \mathrm{~J} 2 \\
\text { Reference }\end{array}$} & annealed & 272 & 564 & 68 & 61 & 171 \\
\cline { 2 - 8 } & quenched & 1224 & 1660 & 18 & 35 & 532 \\
\hline
\end{tabular}

\subsection{Fatigue properties}

Figure 10 shows the $S-N$ diagram of the LMDed specimens and reference material, CMed Type 420J2. Fatigue strengths of the CMed specimens increased by the quenching similar to the tensile strength due to the increase of hardness. It should be noted that the fatigue strengths of the LMDed specimens without interval are nearly comparable to those of the quenched reference material. On the other hand, LMDed specimens with building interval had lower fatigue strengths than those without interval.

Typical fatigue fracture surfaces of the quenched reference material and LMDed specimen without interval are shown in Figs. 11 and 12, respectively. Fatigue crack initiation sites are flat in both materials. It should be emphasized that defect is not seen at the crack initiation site of the LMDed specimen (Fig. 12). It is known that process-induced defects like pores could be fatigue crack initiation sites in the AMed materials, because fatigue crack initiation is sensitive to the stress concentration at defects [12], [27]. In the present study, although fatigue crack initiation sites of six fatigue failed samples in Fig. 10 were examined in detail, defects were not found. Figures 13,14 and 15 are the fatigue fracture surfaces of the LMDed specimens with intervals. In all cases, fatigue cracks initiated at the left side of the interval. A defect was found at the crack initiation site only in Fig. 15, where the size was as small as about 40 $\mu \mathrm{m}$. As mentioned above, fatigue cracks predominantly initiate at defects in AMed materials. For example, the authors conducted fatigue tests using five samples of SLMed Type 630 martensitic stainless steel [12], and eleven samples of electron-beam-melted Ti-6Al-4V [27], and fatigue cracks initiated at the defects in all sixteen samples. However, we found a defect only one case in nine samples as shown in Fig. 15. It indicates that nearly defect-free fabrication could be possible in the present LMD process compared with the other conventional AM processes.

\section{Discussion}

As shown in Fig. 10, interval during deposition process had detrimental effect on the fatigue performances. Fractographic analyses revealed that fatigue cracks predominantly initiated at the area before the interval (Figs. $13 \sim 15$ ). The fatigue crack initiation sites are shown by the cross symbols in the hardness profile of Fig. 7. The sites do not exactly correspond to the location of minimum hardness, while it should be noted that the softened area is wider in the area before the interval. Consequently, the degradation of fatigue strength by the interval can be attributed to the local softening induced by the heat 
history during the interval. The heat history of the building process with interval is as follows. When the building is interrupted, the temperature of the building plate goes down to the room temperature at a slow cooling rate, and subsequently building is resumed, namely melted powder is deposited on the cooleddown plate again. The microstructural features near the interval are almost same as shown in Fig. 6, but it is considered that tempering occurred during slow cool down process during interval, resulting in the local softening. The tempering during interval was also responsible for the wider softened area before the interval (left side of the interval in Fig. 7).

As schematically shown in Fig. 16, interval during deposition process is equivalent to the size of a building object. When the size of the object becomes large, the temperature at a location of the building object could go down to the room temperature during the movement of a laser processing nozzle. Therefore, the design fatigue curves for the LMDed samples can be given as shown in Fig. 17. The upper and lower bounds are design curves for the small and large objects, respectively. If building objects are small and the effect of the interval is negligible, the upper bound can be used for the fatigue design. If building objects are large, and the decrease of the temperature is unknown, the lower bound in Fig. 17 could be used as a conservative design curve. However, if the decrease of the temperature and local softening depending on the size of the building object are monitored, the optimized lower bound can be proposed as schematically shown by a green broken-lined curve in Fig. 17.

\section{Conclusion}

Type 420J1 martensitic stainless steel plates were fabricated using a multitasking LMD machine consisting of additive manufacturing and 5-axis machining center. Subsequently, fully-reversed axial loading fatigue tests were conducted using laser-metal-deposited (LMDed) and conventionallymanufactured (CMed) samples. In some LMDed samples, building intervals were given to investigate the effect of intervals during deposition process on the fatigue properties, and to propose design fatigue curves. The conclusions are as follows.

(1) The hardness and tensile strength of the LMDed samples were slightly higher than those of the quenched and tempered reference material. However, the fatigue strengths of both materials were nearly comparable.

(2) By giving building interval, local softening occurred near the location of the interval. Tempering occurred in the building plate during interval due to the slow cooling rate, resulting in the local softening. The softened area was wider in the area before the interval because of the tempering of the building plate during interval.

(3) Fatigue strengths of the specimens with intervals were inferior to those without interval due to the local softening. Defects were rarely seen at the crack initiation sites of the LMDed specimens irrespective of the intervals. 
(4) S-N curves for the samples with and without intervals were proposed as design fatigue curves for large and small building objects, respectively. That is because building interval in an LMD process could be related to the size of the building objects.

\section{Declarations}

Ethical Approval Not applicable.

Consent to Participate All authors have approved to participate.

Consent to Publish The manuscript has been approved by all authors for publication.

Authors Contributions Y. Uematsu, T. Kakiuchi and R. Sano planed and conducted fatigue test analyses. R. Sasaki, S. Yamamoto and A. Zensho optimized building conditions and built samples. All authors discussed the results and contributed to the final manuscript.

Funding Not applicable.

Competing Interests The authors declare that they have no conflict of interest.

Availability of data and materials Not applicable

\section{References}

1. Herzog R, Seyda V, Wycisk E, Emmelmann C. Additive manufacturing of metals. Acta Materialia 2016;117:371-392

2. Pollock TM, Clarke AJ, Babu SS. Design and tailoring of alloys for additive manufacturing. Metal. Mater. Trans. A 2020;51:6000-6019

3. Dass A, Moridi A. State of the art in directed energy deposition: From additive manufacturing to materials design. Coatings 2019;9:418

4. Liu Y, Li A, Cheng X, Zhang SQ, Wang HM. Effects of heat treatment on microstructure and tensile properties of laser melting deposited AISI 431 martensitic stainless steel. Mater. Sci. Eng.: A, 2016;666:27-23

5. Bandyopadhyay A, Traxel KD. Invited review article: Metal-additive manufacturing-Modelling strategies for application-optimized designs. Additive Manufacturing 2018;22:758-774

6. Zhong C, Liu J, Zhao T, Schopphoven T, Fu J, Gasser A, Schleifenbaum JH. Laser metal deposition of Ti6Al4V-A brief review, Applied Sciences 2020;10(3):764

7. Li W, Karnati S, Kriewall C, Liou F, Newkirk J, Brown Taminger KM, Seufzer WJ. Fabrication and characterization of a functionally graded material from Ti-6Al-4V to SS316 by laser metal deposition. Additive Manufacturing 2017;14:95-104 
8. Yan L, Chen Y, Liou F. Additive manufacturing of functionally graded metallic materials using laser metal deposition, Additive Manufacturing 2019;31:100901

9. Liu Z, Cong W, Kim H, Ning F, Jiang Q, Li T, Zhang HC, Zhou Y. Feasibility exploration of superalloys for AISI 4140 steel repairing using laser engineered net shaping. Procedia Manufacturing. 2017;10:912-922

10. Sun GF, Yao S, Wang ZD, Shen XT, Yan Y, Zhou R, Ni ZH. Microstructure and mechanical properties of HSLA-100 steel repaired by laser metal deposition. Suf. Caot. Technol. 2018;351:198-211

11. Yamamoto S. Application example of super multi-tasking machines equipped with additive manufacturing technology. Journal of the Japan Society for Technology of Plasticity. 2020;3(34):592-596 (in Japanese)

12. Akita M, Uematsu Y, Kakiuchi T, Nakajima M, Kawaguchi R. Defect-dominated fatigue behavior in type 630 stainless steel fabricated by selective laser melting. Mater. Sci. Eng.: A, 2016;666:19-26

13. Carneiro L, Jalalahmadi B, Ashtekar A, Jiang Y. Cyclic deformation and fatigue behavior of additively manufactured 17-4 PH stainless steel. Int. J. Fatigue 2019;123:22-30

14. Nezhadfar PD. Burford E, Anderson-Wedgec K, Zhang B, Shao S, Daniewicz SR, Shamsaei N. Fatigue crack growth behavior of additively manufactured 17-4 PH stainless steel: Effects of build orientation and microstructure. Int. J. Fatigue 2019;123:168-179

15. Nezhadfar PD, Shrestha R, Phan N, Shamsaei N. Fatigue behavior of additively manufactured 17-4 PH stainless steel: Synergistic effects of surface roughness and heat treatment. Int. J. Fatigue 2019;124:188-204

16. Sarkar S, Kumar CS, Nath AK. Effects of heat treatment and build orientations on the fatigue life of selective laser melted 15-5 PH stainless steel. Mater. Sci. Eng.: A, 2019;755:235-245

17. Yadollahi A, Mahmoudi M, Elwany A, Doude H, Bian L, Newman JC Jr. Fatigue-life prediction of additively manufactured material: Effects of heat treatment and build orientation. Fatigue Fract Eng Mater Struct. 2020;43:831-844

18. Bandyopadhyay A, Upadhyayula M, Traxel KD, Onuike B. Influence of deposition orientation on fatigue response of LENS ${ }^{\text {TM }}$ processed Ti6AI4V. Materials Letters 2019;255:126541

19. Gu D, Chen H. Selective laser melting of high strength and toughness stainless steel parts: The roles of laser hatch style and part placement strategy. Mater. Sci. Eng.: A, 2018;725:419-427

20. Nezhadfar PD, Burford E, Anderson-Wedge K, Zhang B, Shao S, Daniewicz SR, Shamsaei N. Fatigue crack growth behavior of additively manufactured 17-4 PH stainless steel: Effects of build orientation and microstructure. Int. J. Fatigue 2019;123:168-179

21. Sarkar S, Kumar CS, Nath AK. Effects of heat treatment and build orientations on the fatigue life of selective laser melted 15-5 PH stainless steel. Mater. Sci. Eng.: A, 2019;755:235-245

22. Sanjari M, Hadadzadeh A, Pirgazi H, Shahriari A, Amirkhiz BS, Kestens LAI, Mohammadi M. Selective laser melted stainless steel CX: Role of built orientation on microstructure and micro-mechanical properties. Mater. Sci. Eng.: A, 2020;786:139365 
23. Delroisse P, Jacques PJ, Maire E, Rigo O, Simar A. Effect of strut orientation on the microstructure heterogeneities in AlSi10Mg lattices processed by selective laser melting. Scripta Materialia 2017;141:32-35

24. Xu W, Brandt M, Sun S, Elambasseril J, Liu Q, Latham,K, Xia K, Qian M. Additive manufacturing of strong and ductile $\mathrm{Ti}-6 \mathrm{Al}-4 \mathrm{~V}$ by selective laser melting via in situ martensite decomposition. Acta Materialia 2015;85:74-84

25. Liu Y, Liu C, Liu W, Ma Y, Zhang C, Liang C, Cai Q. Laser powder deposition parametric optimization and property development for Ti-6Al-4V alloy, J. Mater. Eng. Perf. 2018;27(11):5613-5621

26. Stoll P, Spierings A, Wegener K. Impact of a process interruption on tensile properties of SS $316 \mathrm{~L}$ parts and hybrid parts produced with selective laser melting. Int. J. Adv. Manuf. Tech. 2019;103:367376

27. Kakiuchi T, Kawaguchi R, Nakajima M, Hojo M, Fujimoto K, Uematsu Y. Prediction of fatigue limit in additively manufactured Ti-6Al-4V alloy at elevated temperature. Int. J. Fatigue 2019;126:55-61

\section{Figures}



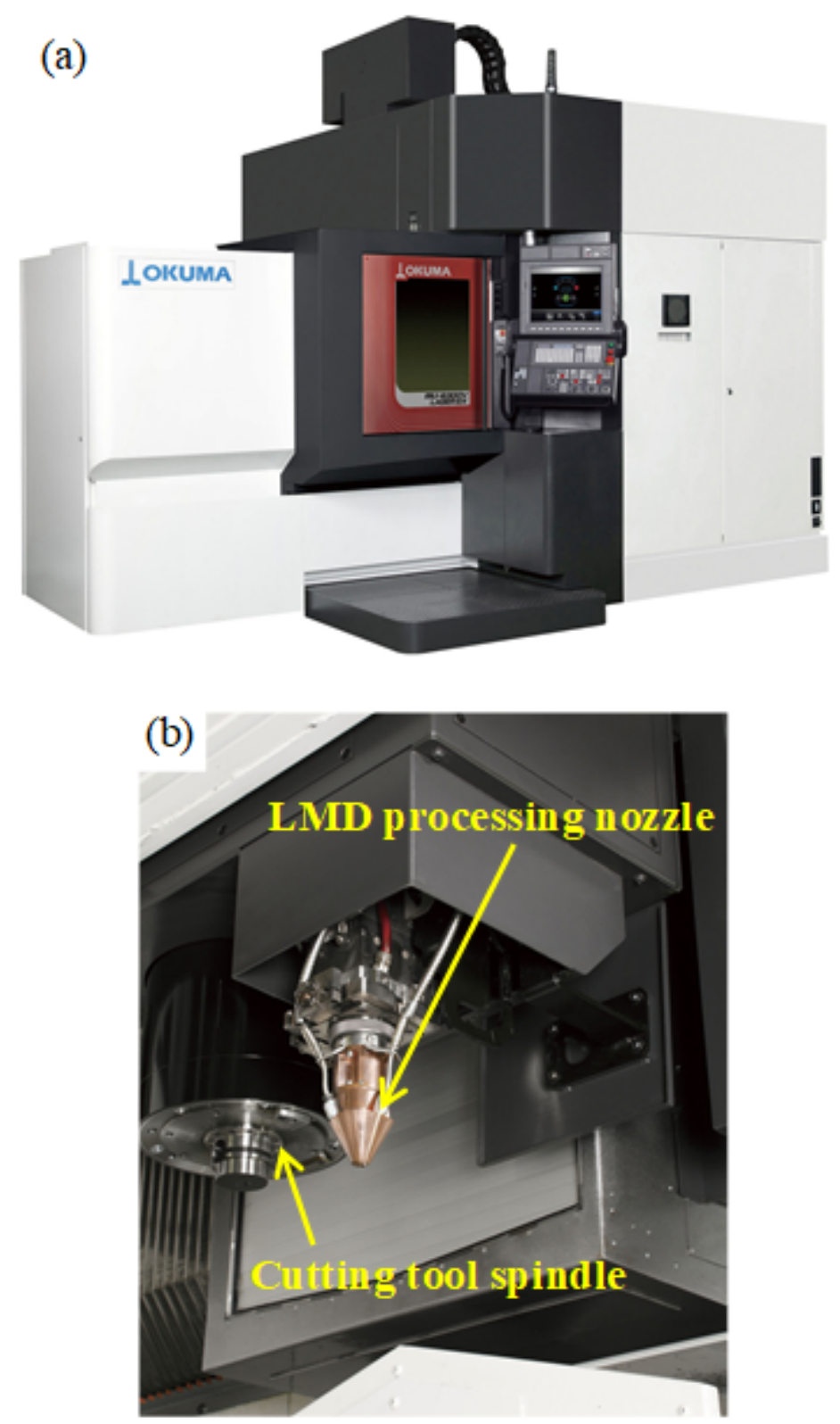

\section{Figure 1}

Overview of multitasking LMD machine (a) MU-6300V LASER EX (OKUMA Corporation), (b) Processing nozzle and cutting tool spindle in the same processing area. 

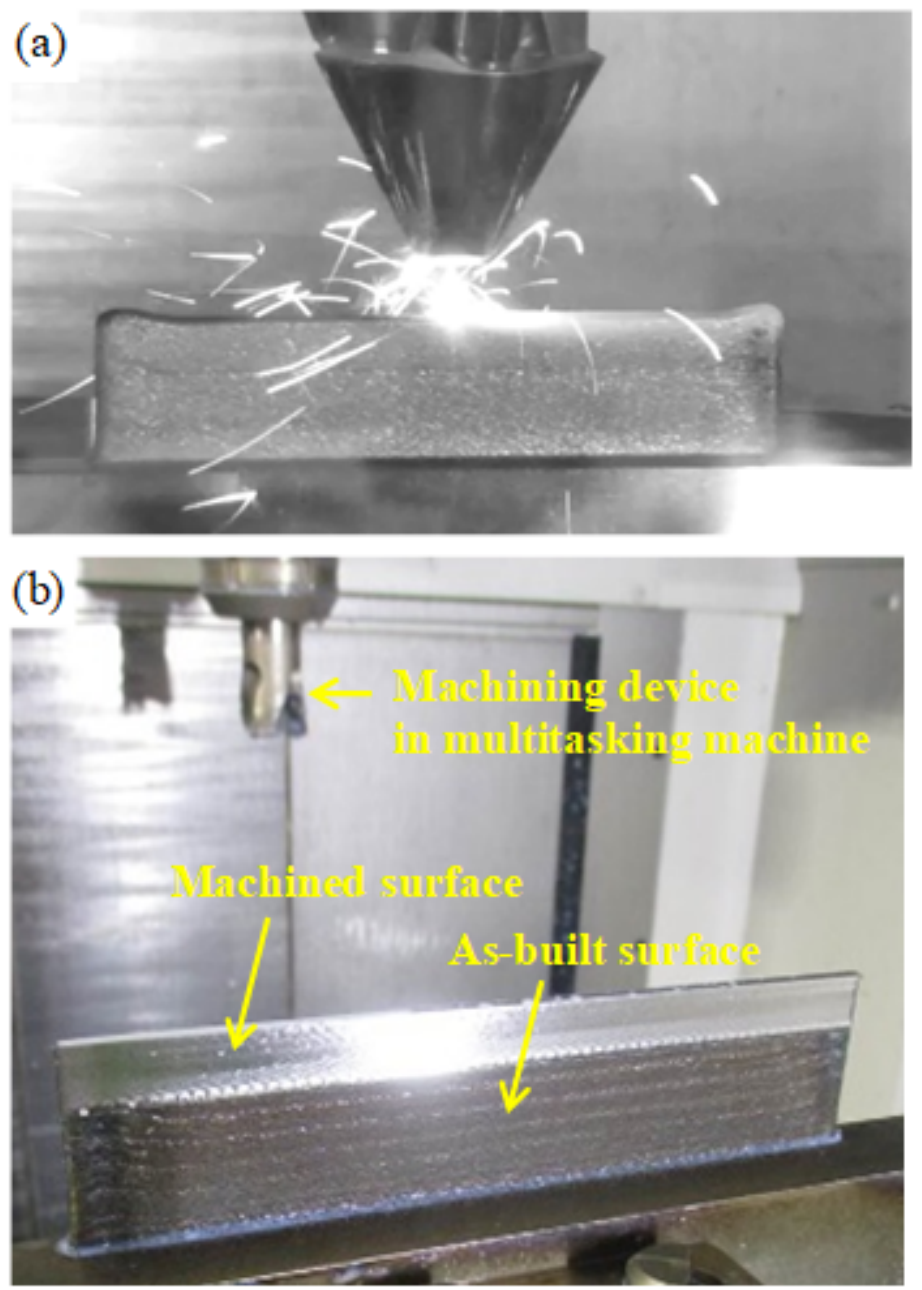

(c)

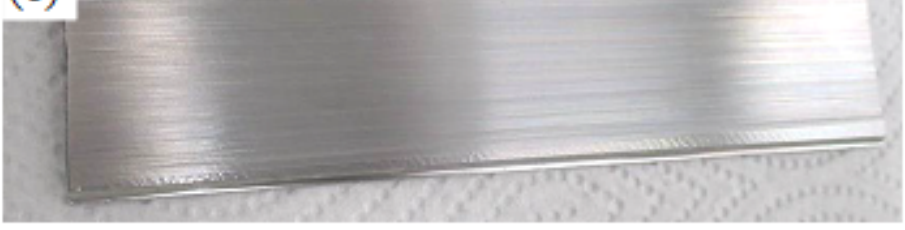

\section{Figure 2}

Specimen fabrication procedure: (a) Deposition of powder on the base plate, (b) Machining in the processing area of multitasking machine, (c) A plate cut from the base plate. 


\section{The line where interval was given.}

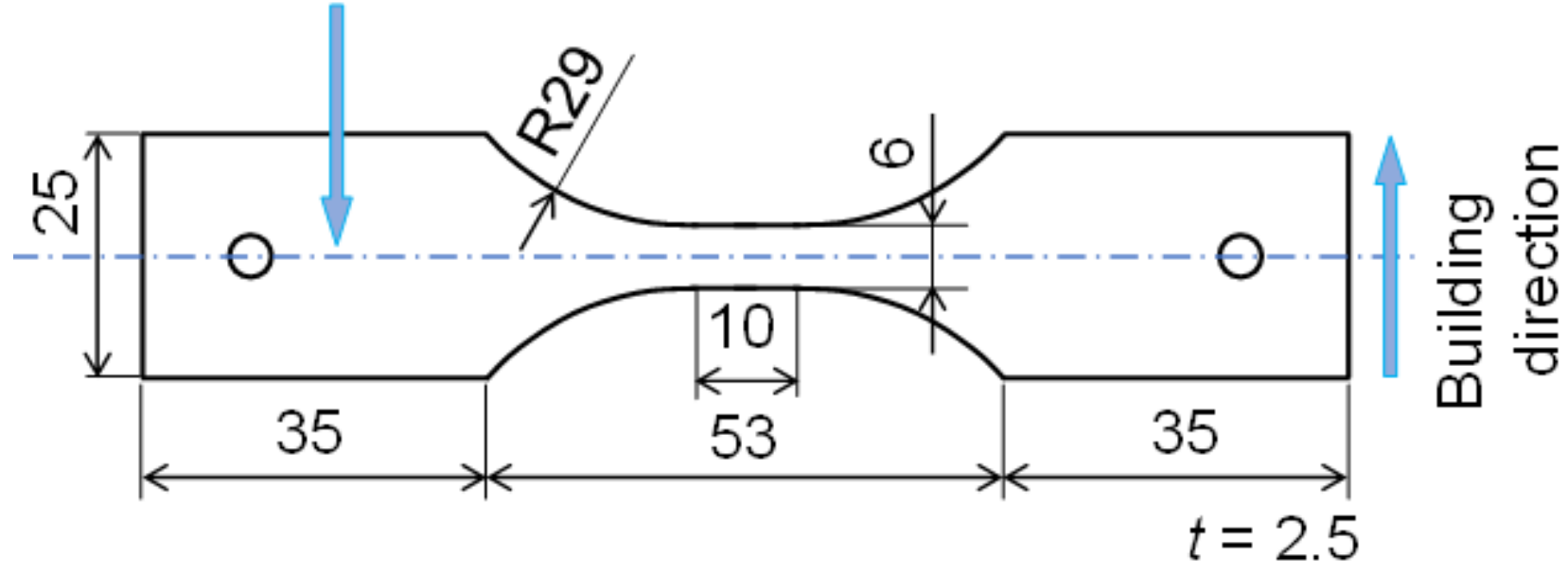

Figure 3

Fatigue specimen configuration showing the building direction and dashed line where building interval was given.
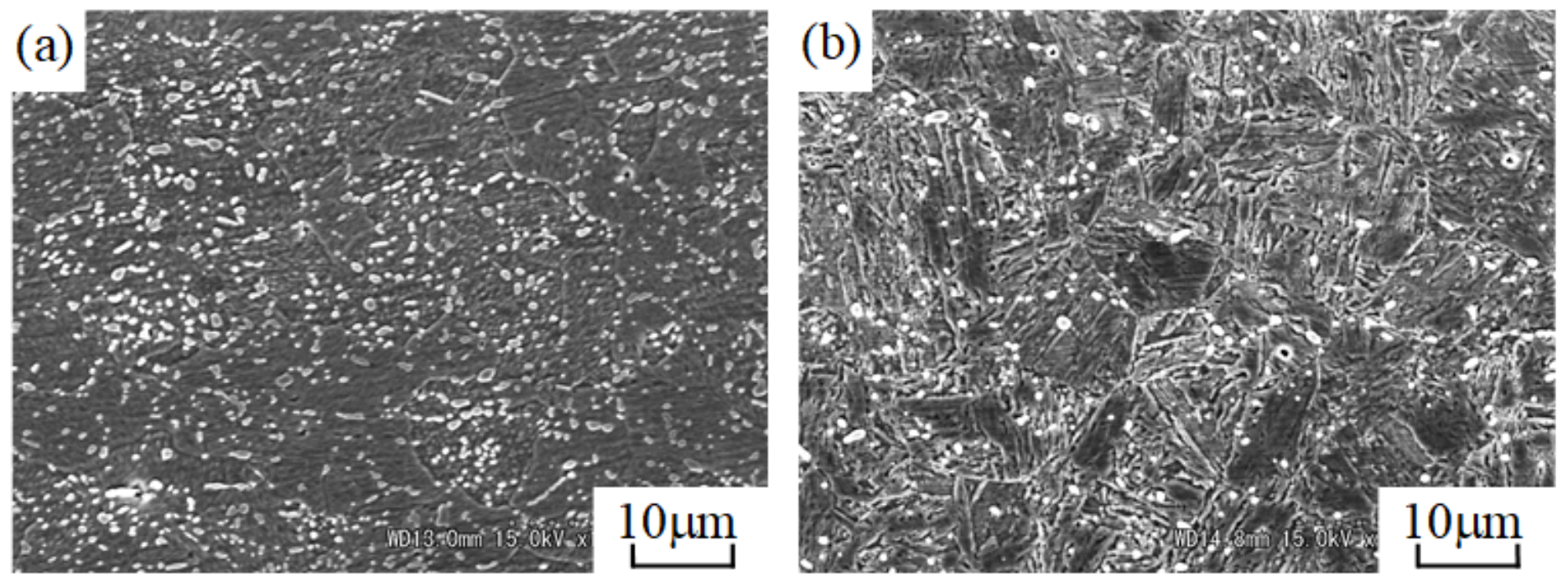

\section{Figure 4}

Microstructures of reference material, conventionally manufactured Type 421J2: (a) As-received (annealed), (b) Quenched and tempered. 

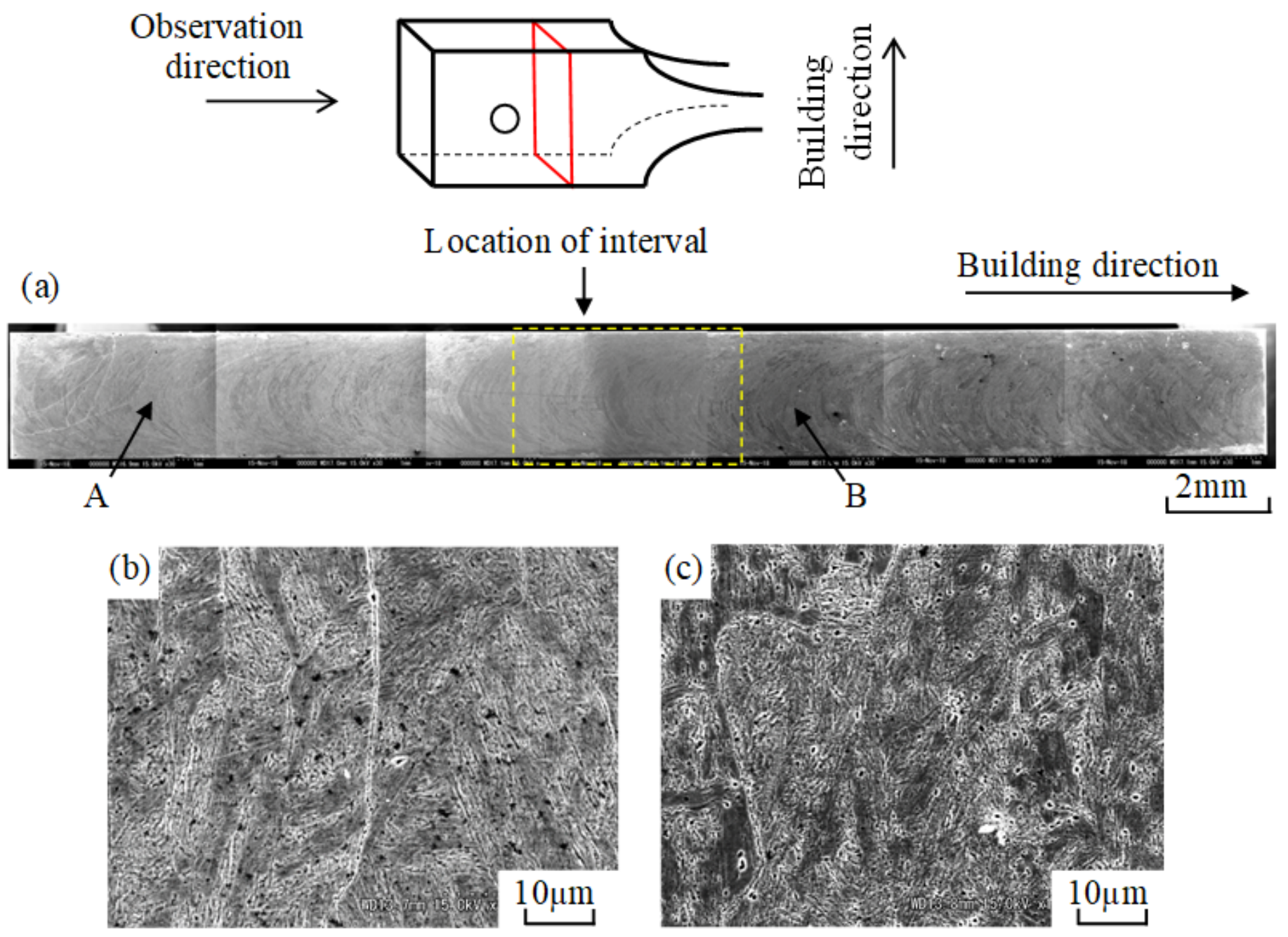

Figure 5

Microstructures of LMDed Type 421J1: (a) Overall view, (b) and (c) are the magnified views at " $A$ " and "B" in Fig. (a), respectively. 


\section{Location of interval}
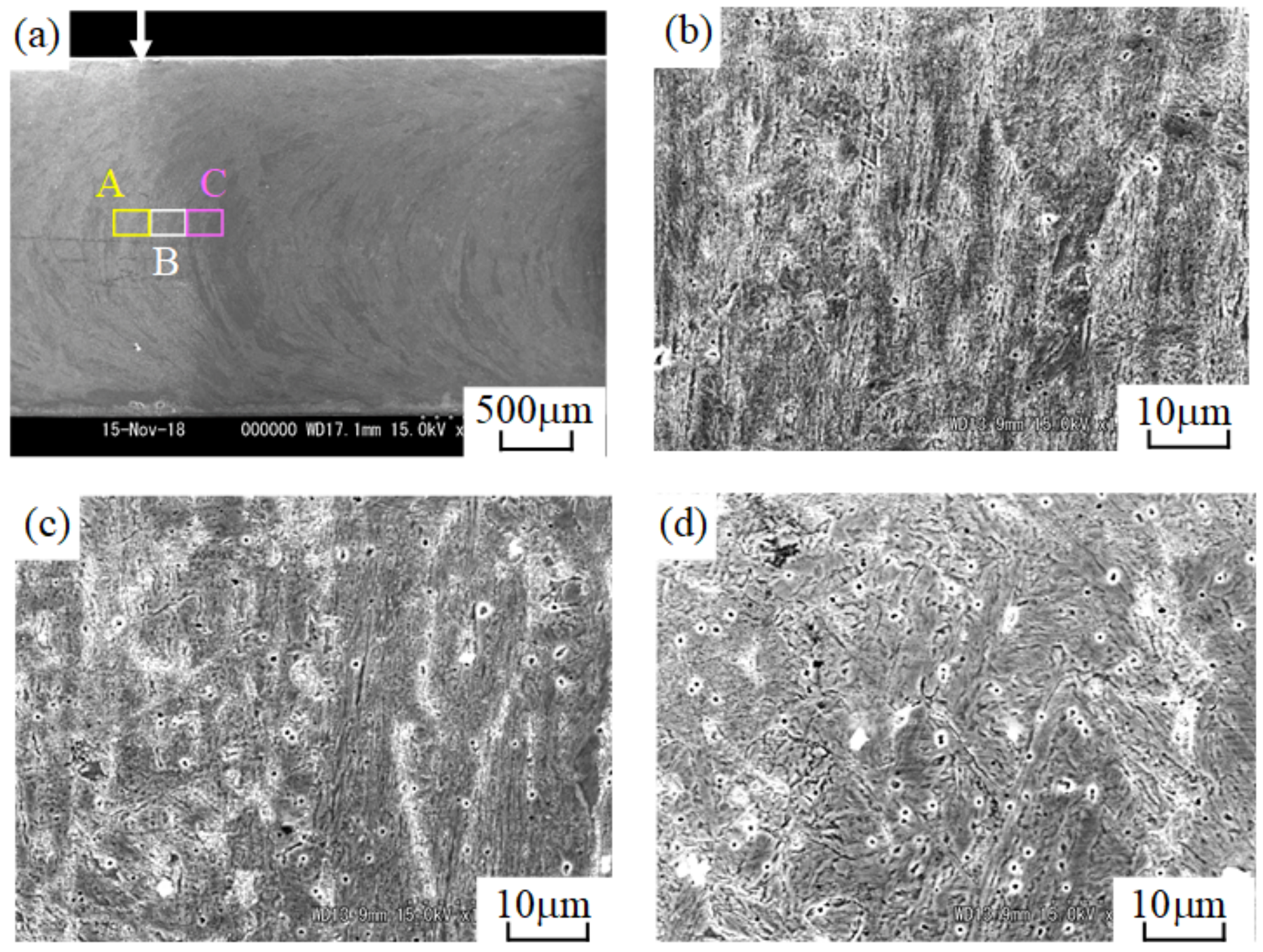

\section{Figure 6}

Microstructure in the rectangular area of Fig. 5(a), (b), (c) and (d) are the magnified views at " $\mathrm{A}$ ", " $\mathrm{B}$ " and "C" in Fig. (a), respectively. 


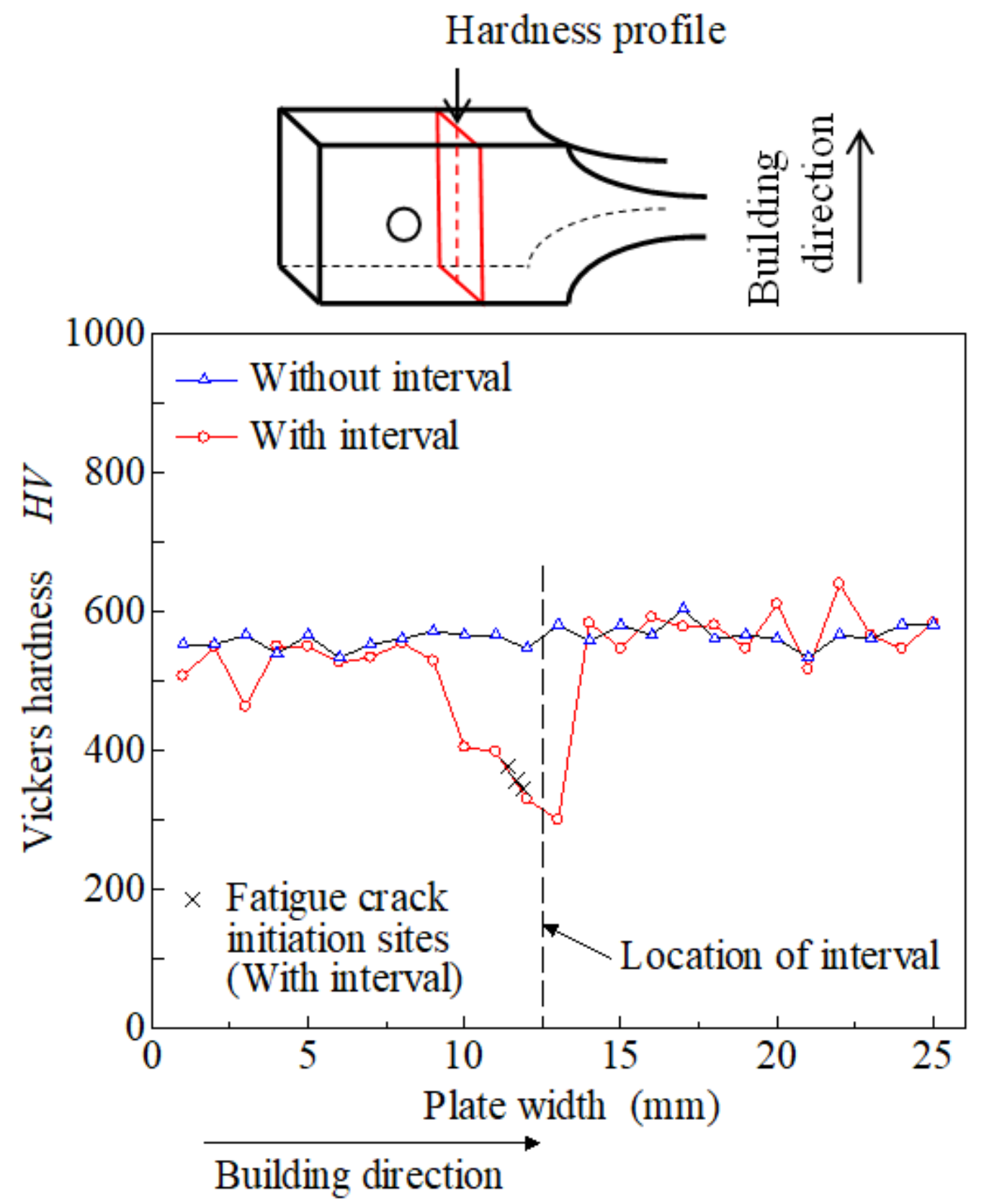

Figure 7

Hardness profiles of LMDed samples with and without interval. 


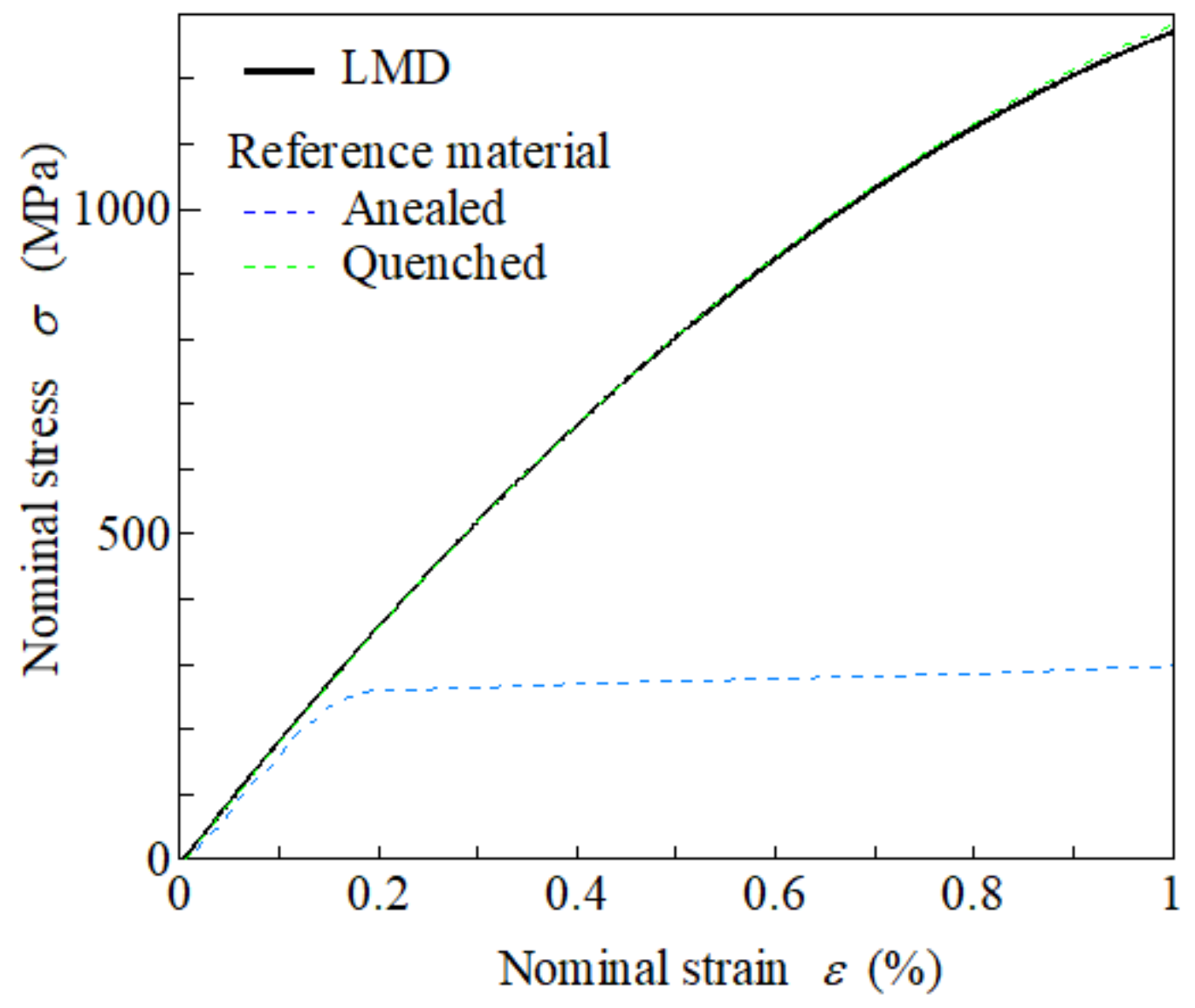

Figure 8

Stress-strain curves. 


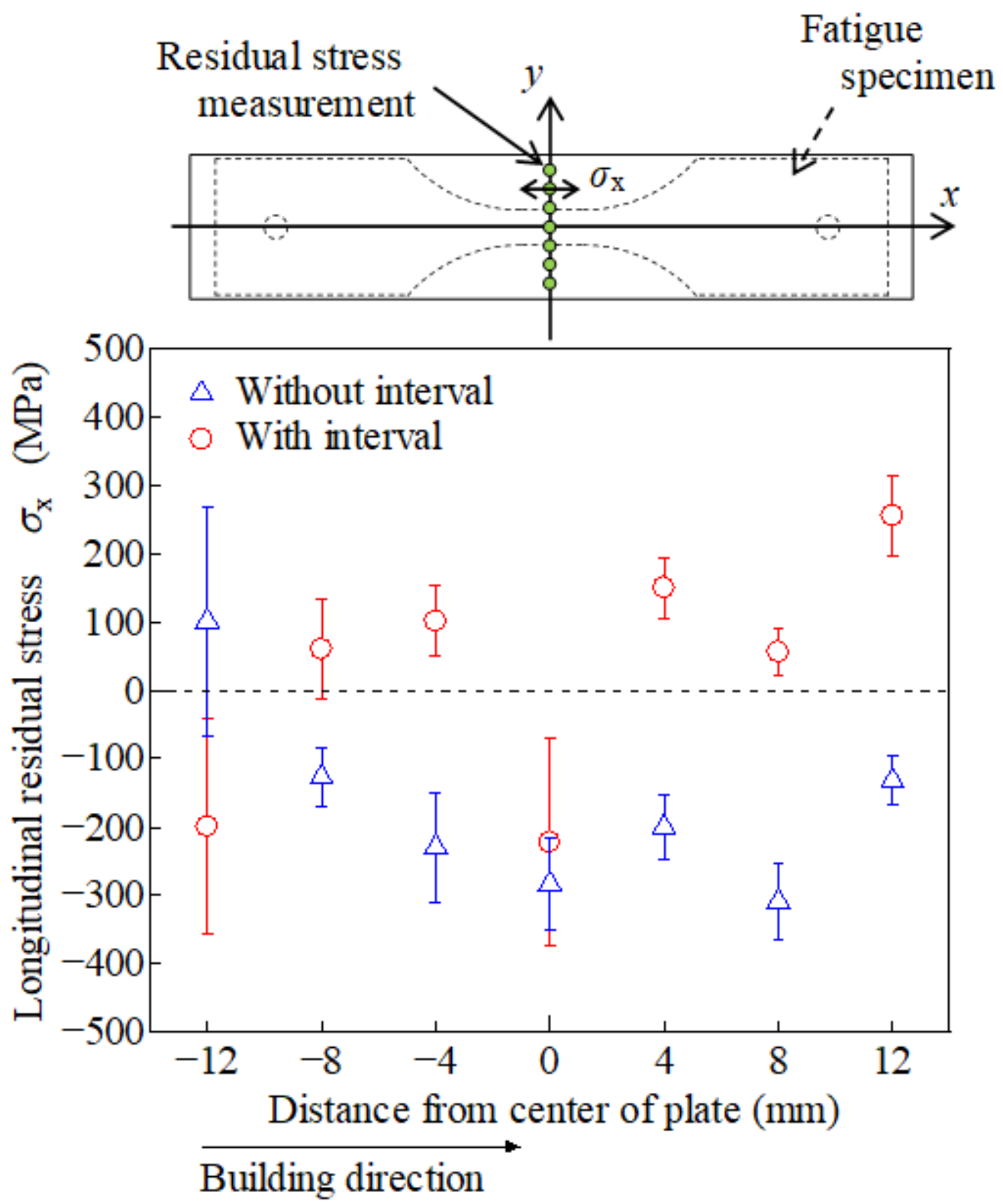

Figure 9

Longitudinal residual stress of the plates with and without interval. 


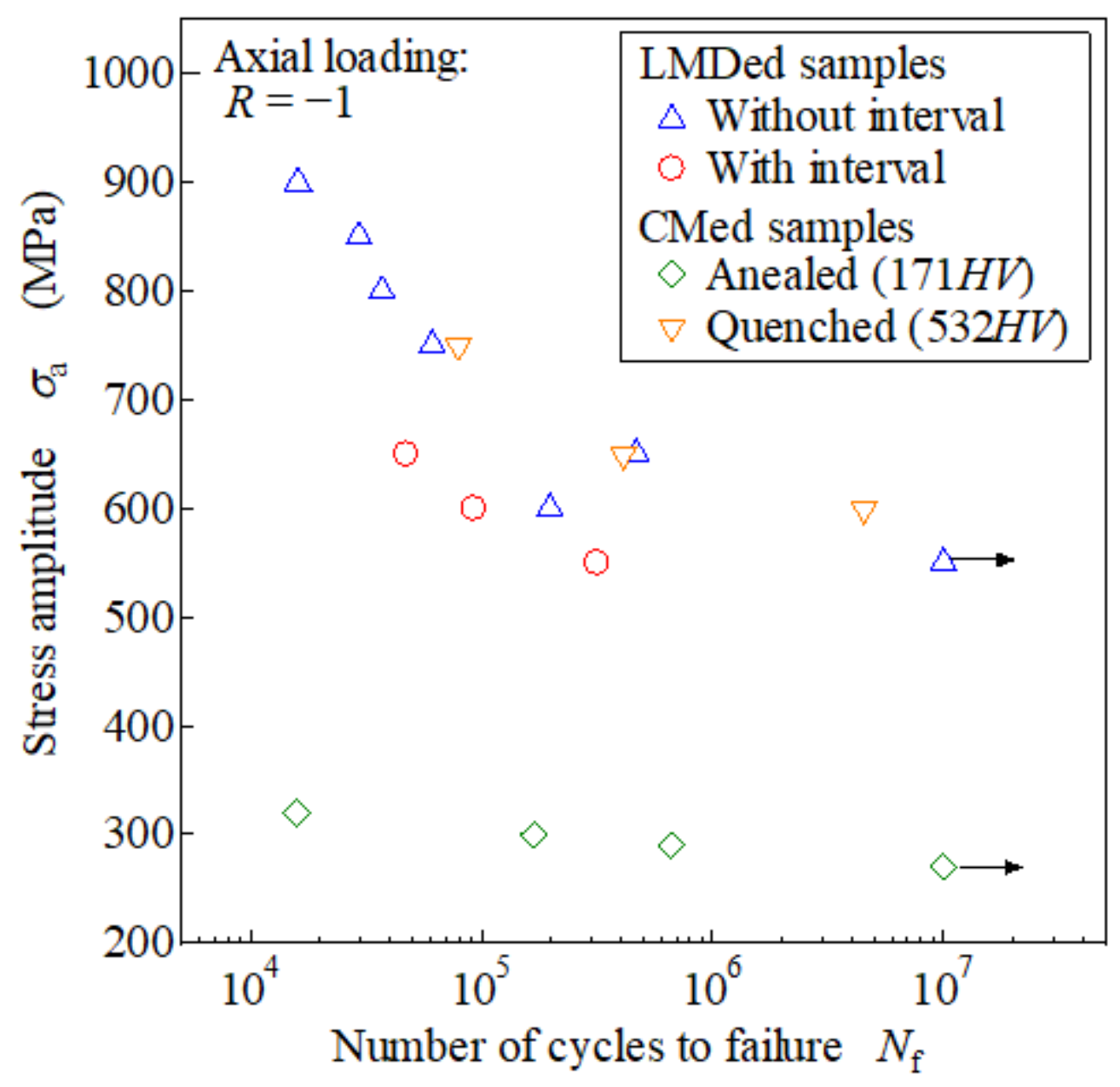

Figure 10

S-N diagram. 


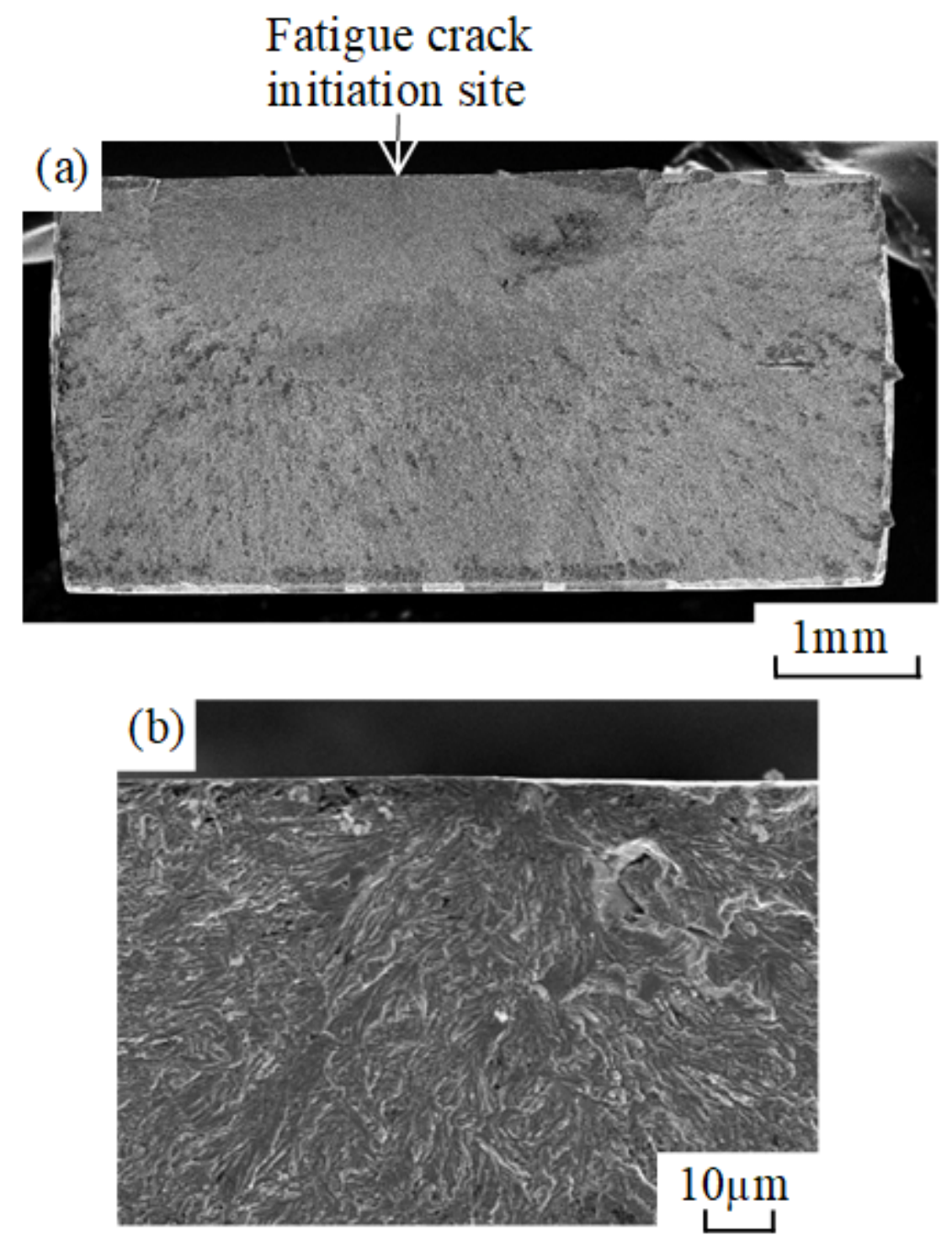

\section{Figure 11}

Fatigue fracture surface of quenched reference material, Type 420J1: (a) Macroscopic view, (b) Magnified view at crack initiation site. Test condition: $\sigma a=600 \mathrm{MPa}, \mathrm{Nf}=4.53 \times 106$. 


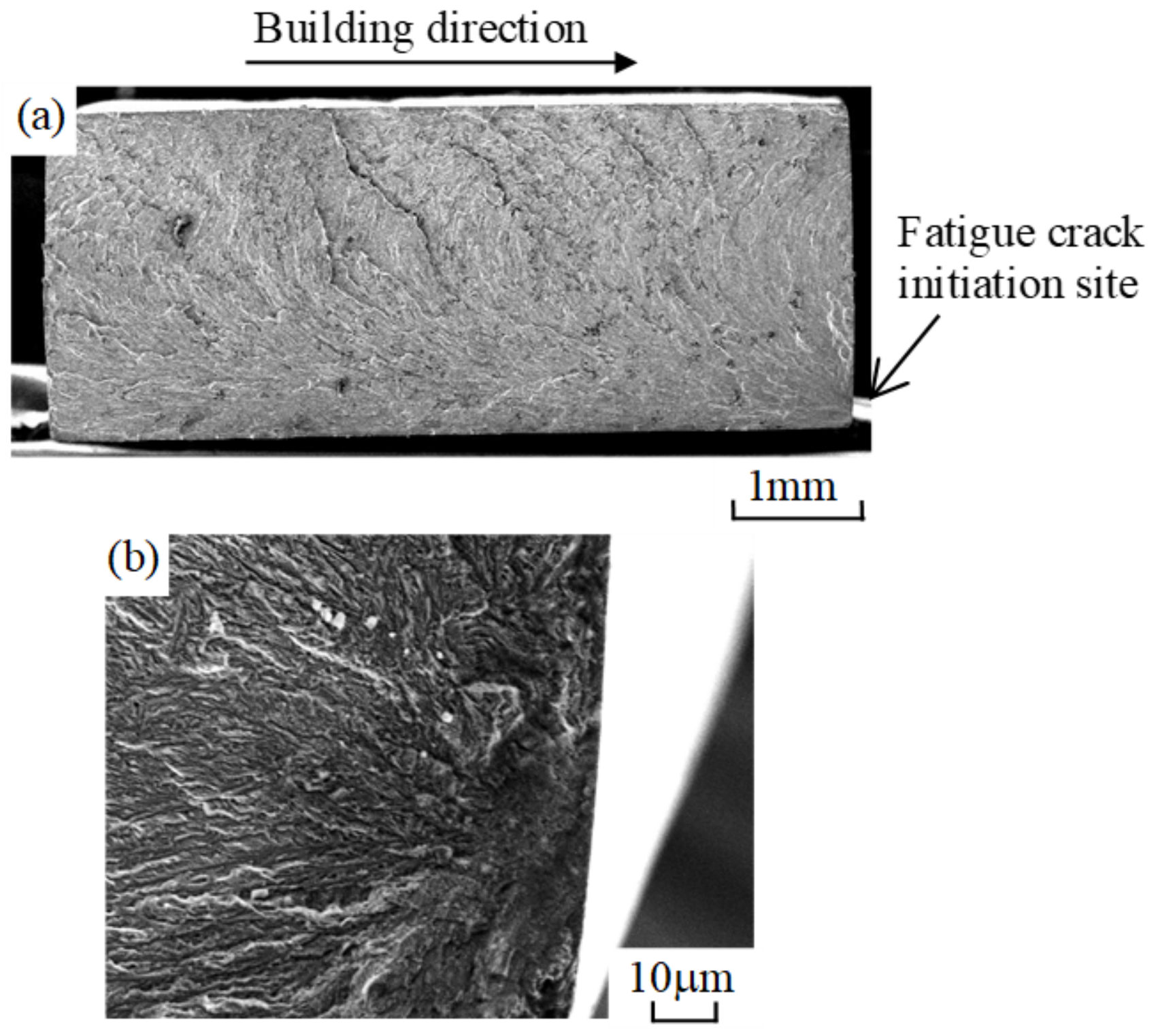

Figure 12

Fatigue fracture surface of LMDed specimen without interval: (a) Macroscopic view, (b) Magnified view at crack initiation site. Test condition: $\sigma a=850 \mathrm{MPa}, \mathrm{Nf}=2.94 \times 104$. 


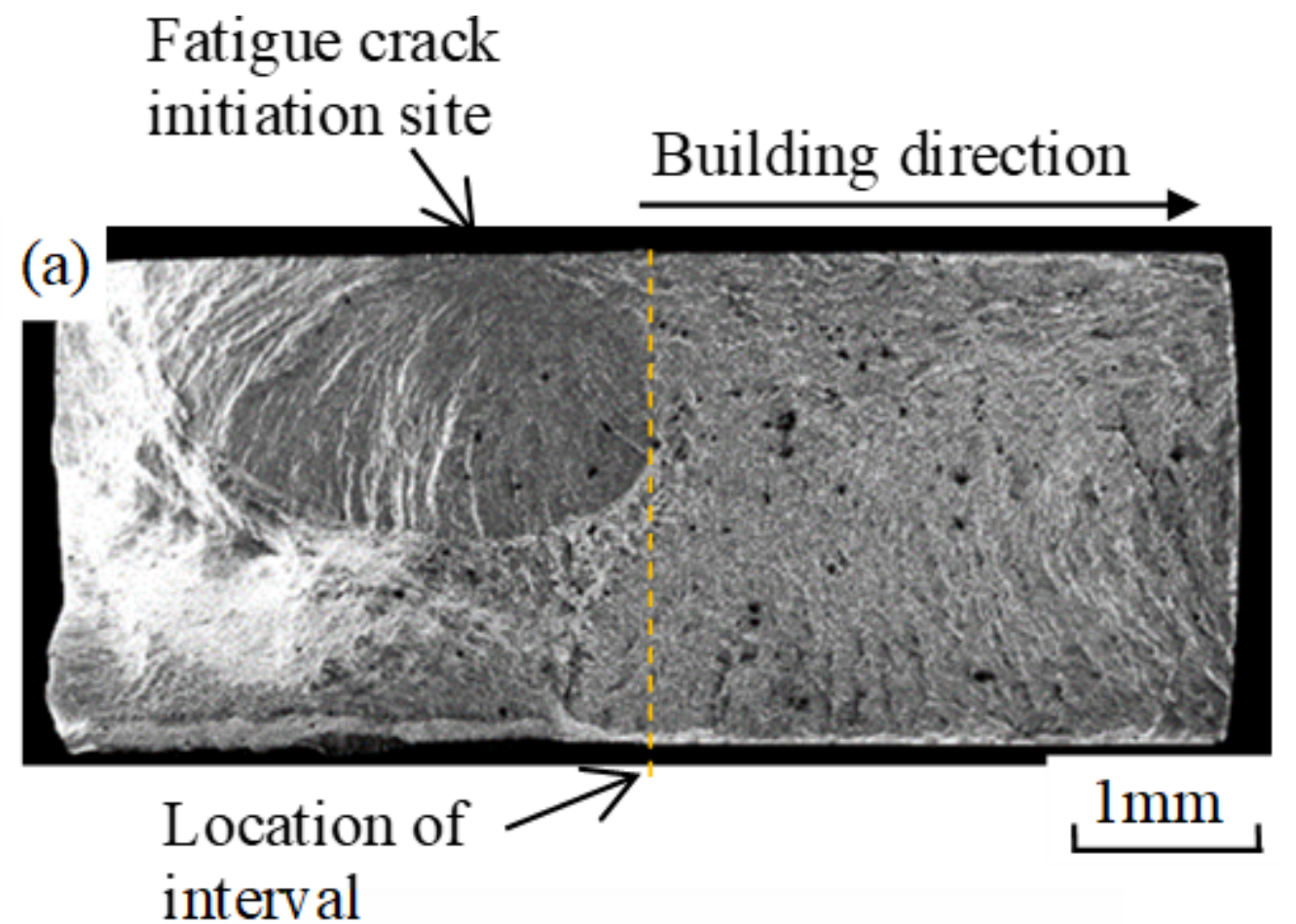

(b)

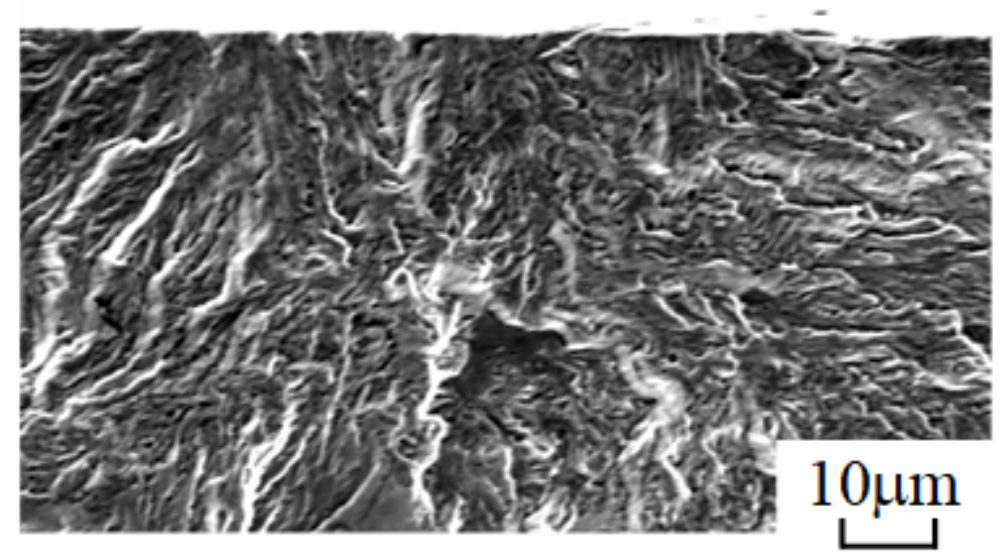

Figure 13

Fatigue fracture surface of LMDed specimen with interval: (a) Macroscopic view, (b) Magnified view at crack initiation site. Test condition: $\sigma a=650 \mathrm{MPa}, \mathrm{Nf}=4.72 \times 104$. 

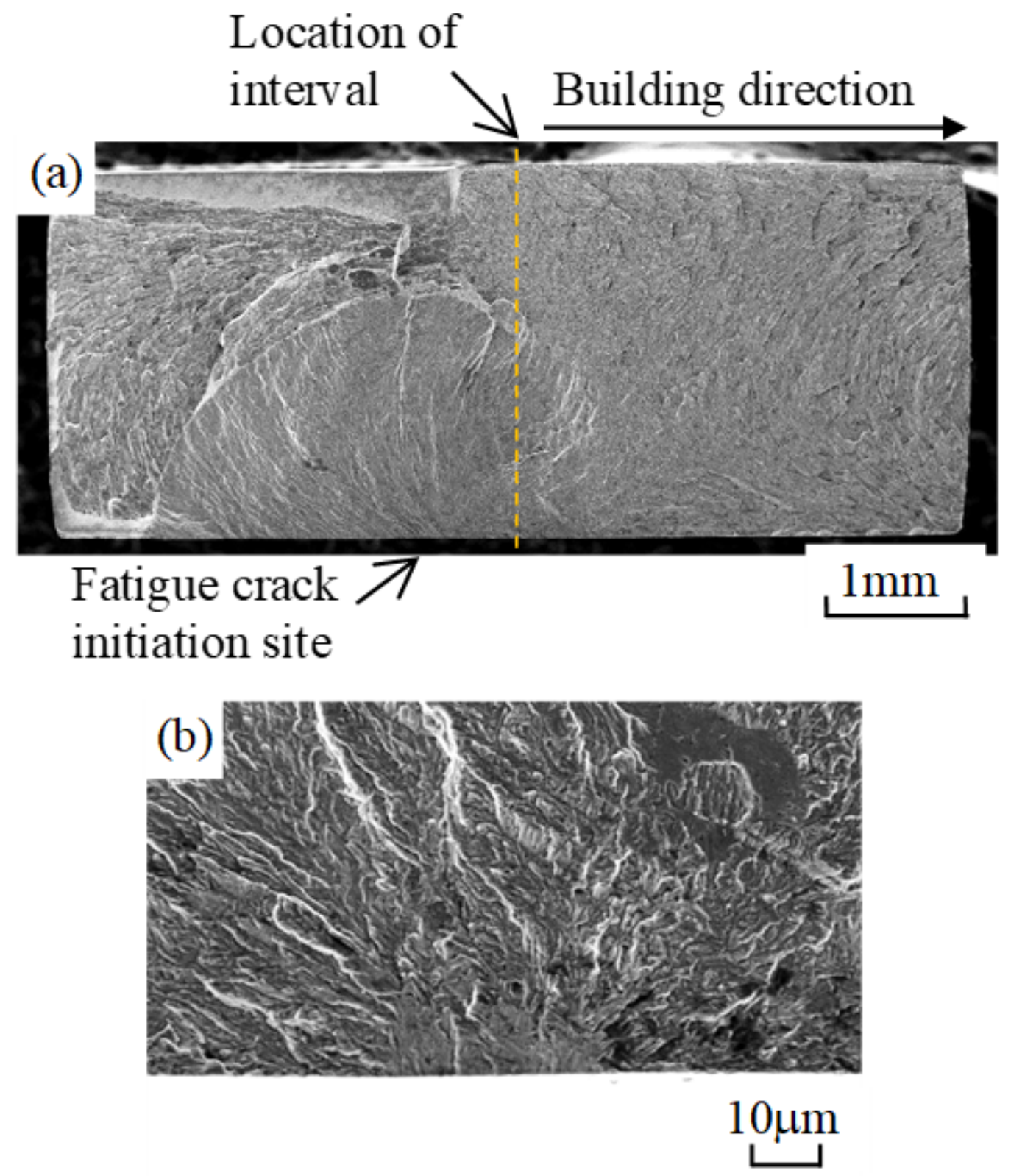

Figure 14

Fatigue fracture surface of LMDed specimen with interval: (a) Macroscopic view, (b) Magnified view at crack initiation site. Test condition: $\sigma a=600 \mathrm{MPa}, \mathrm{Nf}=9.28 \times 104$. 

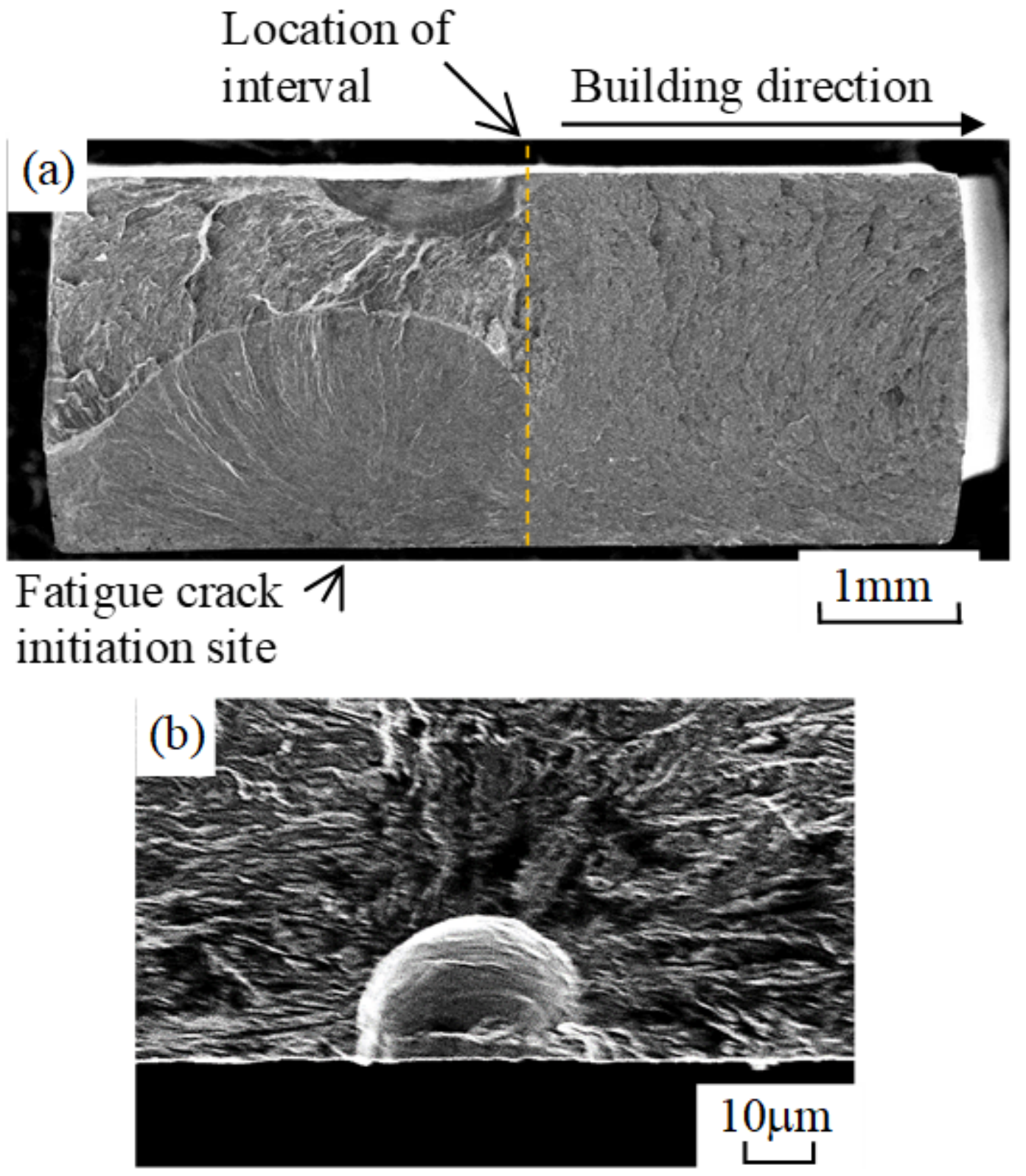

Figure 15

Fatigue fracture surface of LMDed specimen with interval: (a) Macroscopic view, (b) Magnified view at crack initiation site. Test condition: $\sigma a=550 \mathrm{MPa}, \mathrm{Nf}=3.16 \times 105$. 

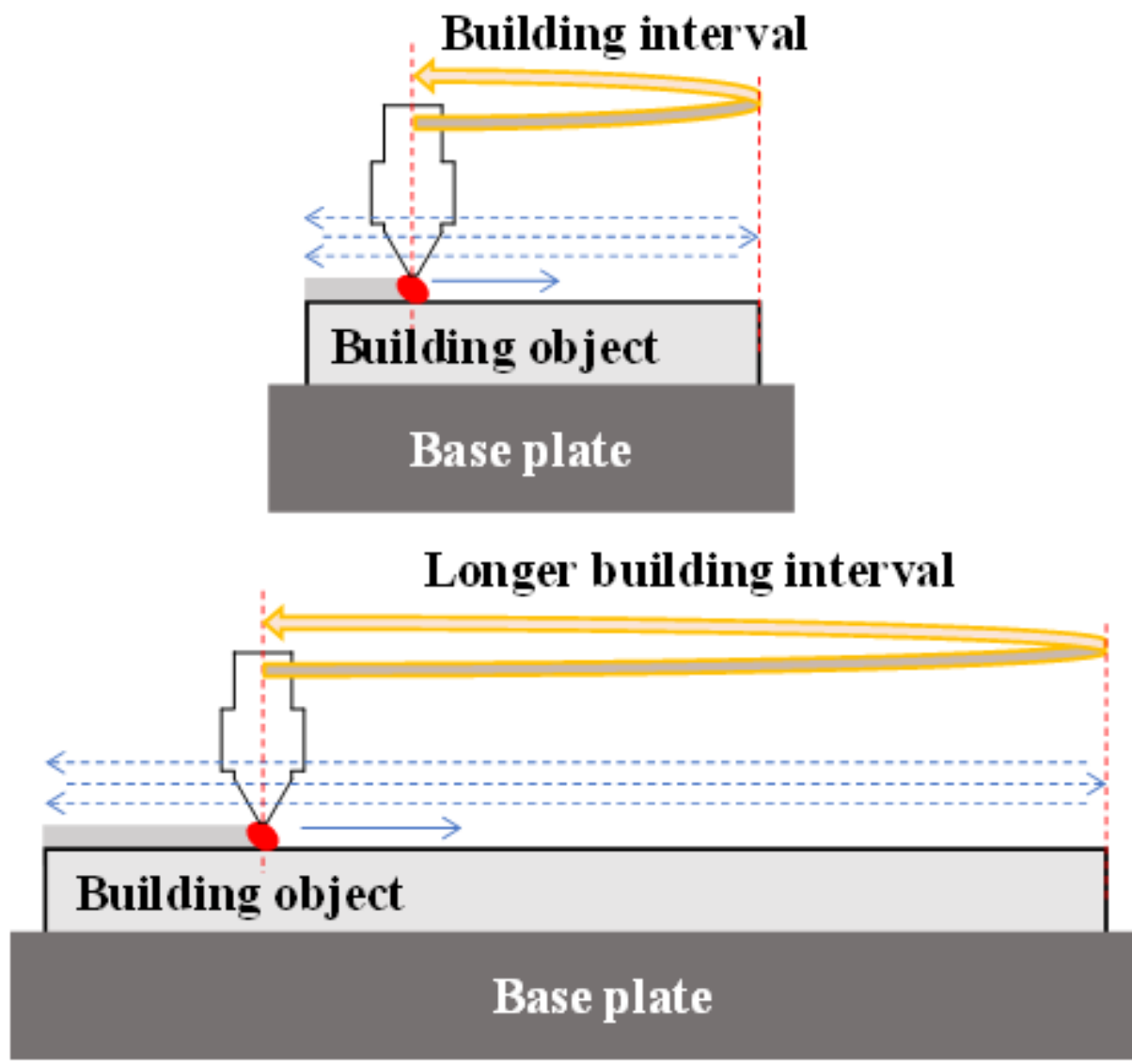

Figure 16

Schematic illustration showing the relationship between building interval and the size of building object. 


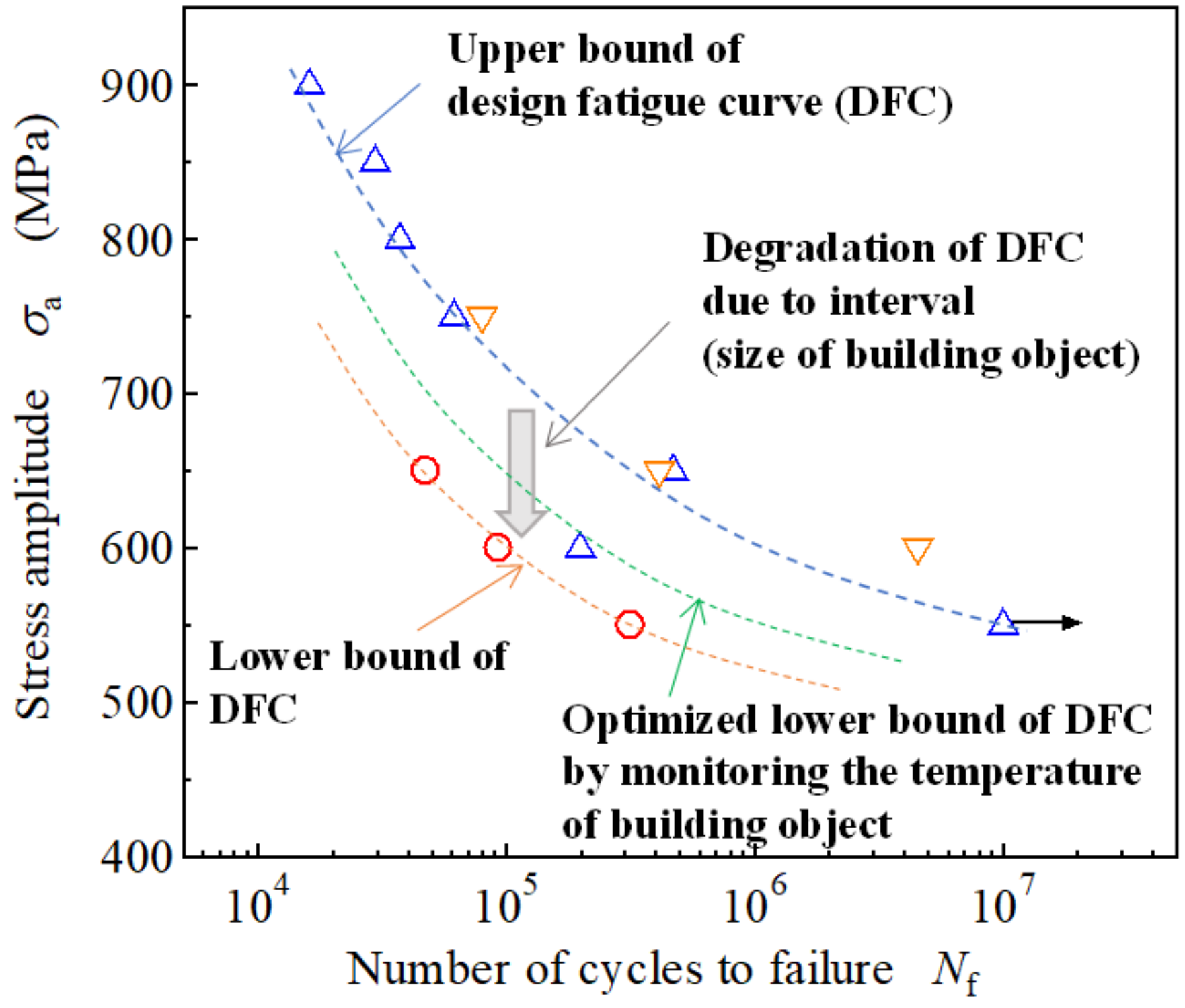

Figure 17

Schematic illustration of the proposal of fatigue design curves. 